\title{
Fertility in male sheep: modulators of the acute effects of nutrition on the reproductive axis of male sheep
}

\author{
D. Blache, S. Zhang and G. B. Martin \\ School of Animal Biology, Faculty of Natural and Agricultural Sciences, University of \\ Western Australia, Crawley 6009, Australia
}

\begin{abstract}
Animals adjust the time of year that they reproduce through their ability to perceive and respond to critical aspects of their environment, such as photoperiod, nutrition or the socio-sexual milieu, and their genotype determines the degree of response to each stimulus. Ultimately, information from environmental cues filters through to the $\mathrm{GnRH}$ neurones in the brain which are the primary regulator of fertility. Each of these cues has been studied in isolation and the mechanisms by which they affect GnRH secretion are now better, if not fully, understood. In the field, the brain centres that control GnRH must integrate information from all cues at any given time before 'formulating a reproductive decision'. In this review, the effect of this integration is illustrated by showing how the acute $\mathrm{GnRH}$ response to a nutritional signal can be modulated by genotype, photoperiod and social cues, to the point of being completely blocked under some circumstances. Candidate pathways that may mediate these modulatory effects at both the whole body and brain have been proposed, although none of these pathways are confirmed and some have not yet been studied. As a guide for further research, we propose a working model that integrates the inputs and explains the interactions between them.
\end{abstract}

\section{Introduction}

As with all species, sheep have evolved to maximize their chances of successful reproduction, whatever the environmental conditions. Over the last 15 years, we have been studying the control of fertility by nutrition in the mature male sheep using two approaches, one that could be seen as reductionist and the other holistic. The reductionist approach ains at understanding the physiological mechanisms through which nutritional signals affect the reproductive system, whereas the holistic approach aims at understanding the interactions between nutrition, genetic and other environmental factors in the control of fertility. This review focuses on the more holistic studies, but also presents developments that have led to the amalgamation of the two approaches. This review starts with a brief description of the experimental model that we use in all of our studies and a concise review of the endocrine pathways involved, before discussing three modulators of the effect of nutrition on the secretion of GnRH-LH and 
(a)
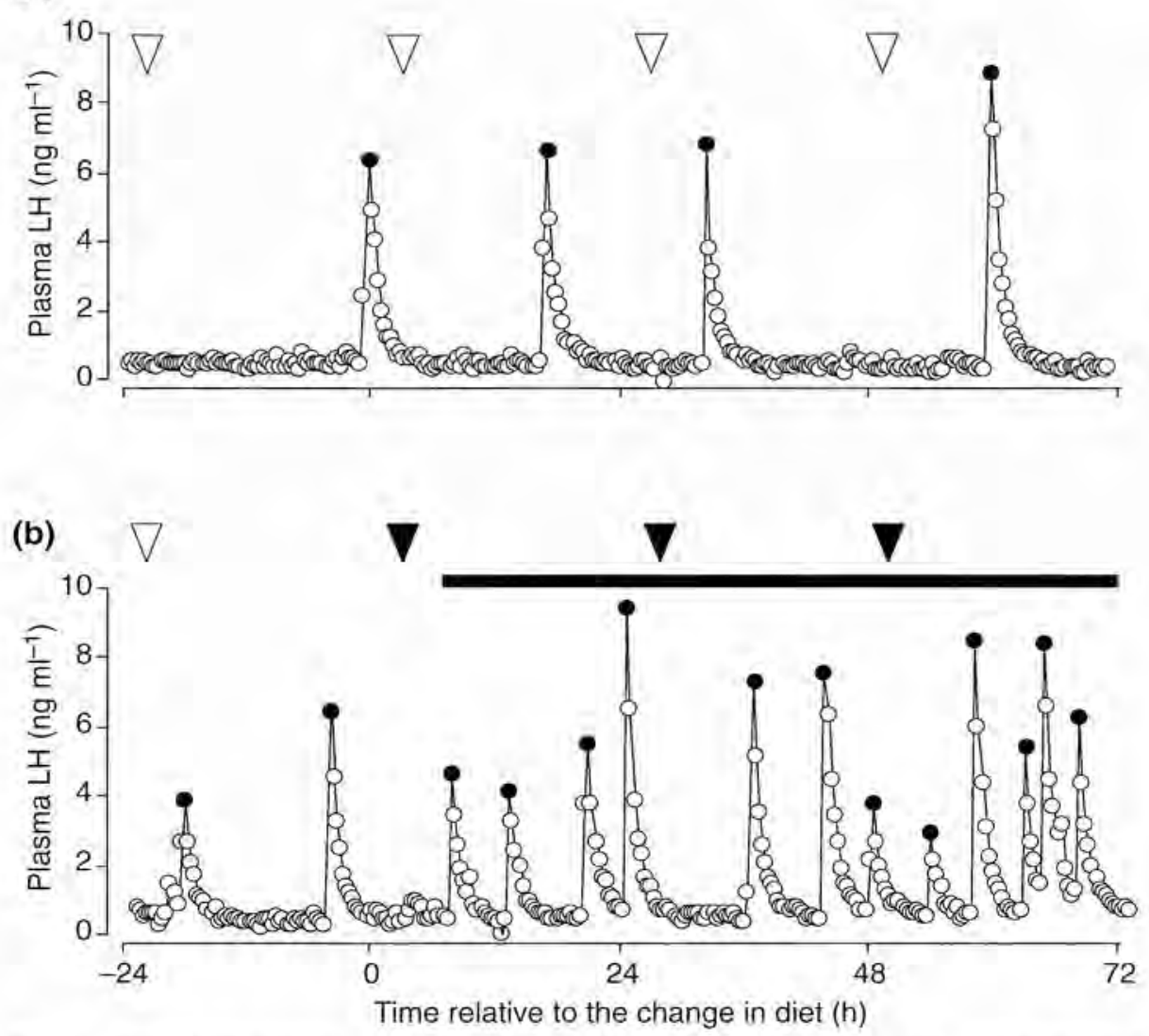

Fig. 1. Profiles of plasma LH concentrations in rams fed (a) a maintenance diet or (b) a twice maintenance diet from time $=0 \mathrm{~h}$. Arrowheads indicate feeding times. Before $0 \mathrm{~h}$, both rams were fed the maintenance diet (open arrowheads). Closed circles indicate significant pulses of $\mathrm{LH}$. The horizontal bar indicates when the $\mathrm{LH}$ pulse frequency had doubled in a moving window of $24 \mathrm{~h}$ compared with the control period of $24 \mathrm{~h}$ before $0 \mathrm{~h}$ (D. Blache and S. Zhang, unpublished).

the physiological mechanisms that could be involved in these interactions. Finally, by way of conclusion, we propose a theoretical model that accounts for these interactions.

\section{The model: the mature male sheep fed lupin grain}

Our experimental model is based on the short-term response of the hypothalamic-pituitarytesticular axis of the mature male Merino sheep to an acute change in nutrition (for reviews, see Martin et al., 1994a; Blache et al., 2002). In brief, suddenly increasing the level of nutrition by supplementing a maintenance diet with a highly digestible feed, such as lupin grain (Lupinus angustifolius), increases the frequency of $\mathrm{LH}$ pulses (and, by inference, GnRH) by two- to threefold within $6-8 \mathrm{~h} \mathrm{(Fig.} \mathrm{1).} \mathrm{If} \mathrm{the} \mathrm{dietary} \mathrm{treatment} \mathrm{is} \mathrm{maintained,} \mathrm{plasma} \mathrm{concentrations}$ of $\mathrm{FSH}$ increase within 10-11 days (Fig. 2), reflecting the normal delay between an increase in GnRH secretion and a pituitary FSH response (Lincoln, 1979). High LH pulse frequencies are maintained for only about 4 weeks, by which time there is a decline back to normal 

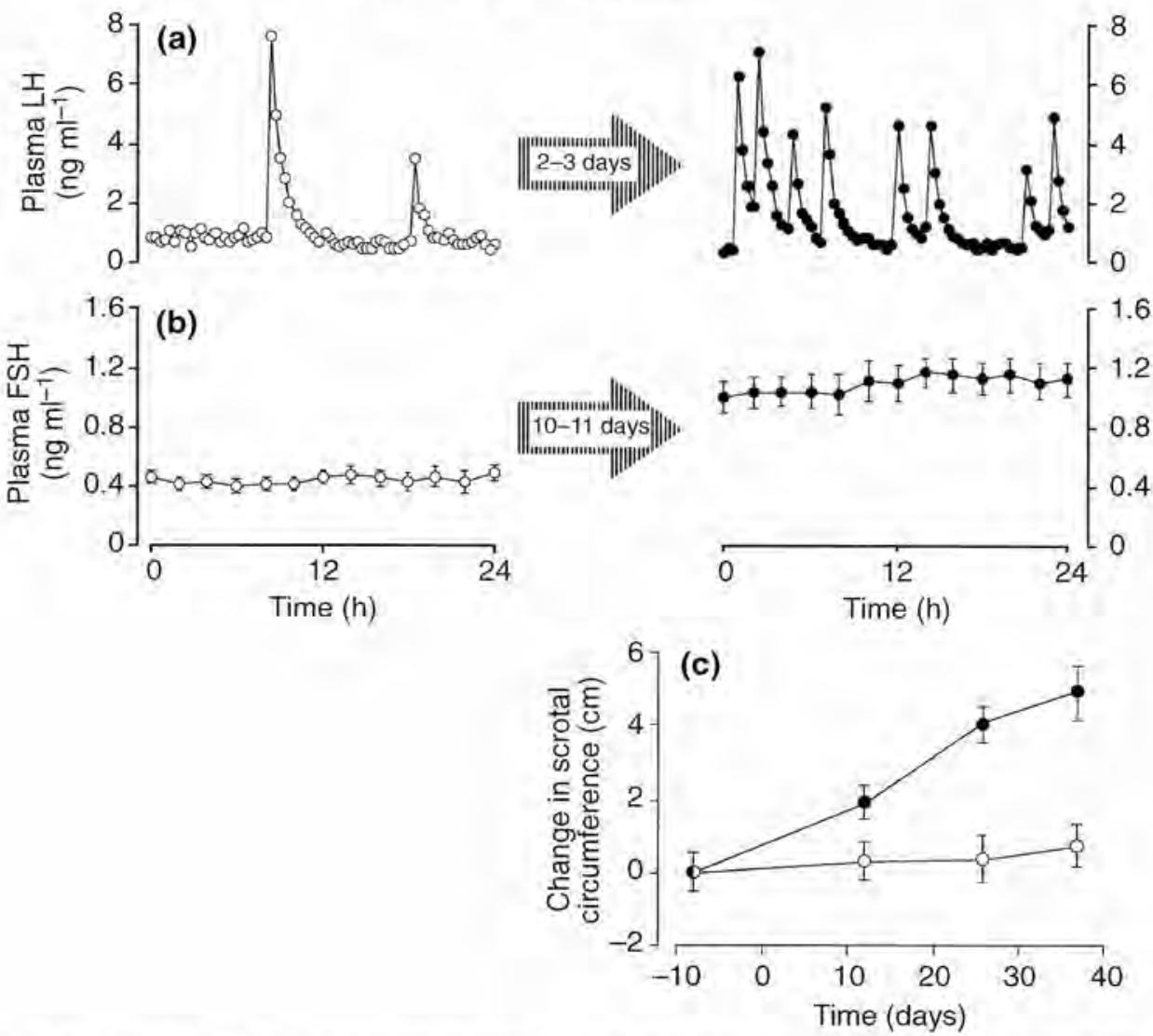

Fig. 2. Short-, medium- and long-term effects of nutrition on the reproductive axis in the mature male Merino sheep (the 'lupin effect'); (0) maintenance diet; $(\bullet)$ maintenance diet supplemented with highly digestible feed (lupin grain). (a) The frequency of LH pulses increases within 2-3 days after change of diet (short-term), whereas (b) the plasma concentrations of FSH increase after about 10-11 days (medium-term) and (c) scrotal circumference increase over a month (long-term).

values despite the maintenance of high-energy intake (Tjondronegoro et al., 1996). However, the outcome for fertility is not jeopardized because testicular size and sperm production continue to increase for several months, or at least as long as the high energy diet is offered (Fig. 2; Martin et al., 1994a). Indeed, there is an obvious time component in the nature of the responses of the reproductive axis: the response for $\mathrm{GnRH}-\mathrm{LH}$ and testosterone is short-term, measurable over a scale of hours; the FSH response and the fade-out of the $\mathrm{LH}$ response are medium-term, occupying a few weeks; the increase in sperm production requires months (Martin et al., 1994a,b). This review focuses on the short-term effect on GnRH-LH, beginning with a brief summary of our findings and our current hypotheses on the mechanisms involved.

\section{Physiological mechanisms mediating the 'lupin effect'}

In the reductionist aspects of our research, it has been possible to dissect parts of the mechanism underlying the long-and short-term responses of the reproductive axis to changes in nutritional status (for reviews, see Blache et al., 2000, 2002). Briefly, by combining nutritional 


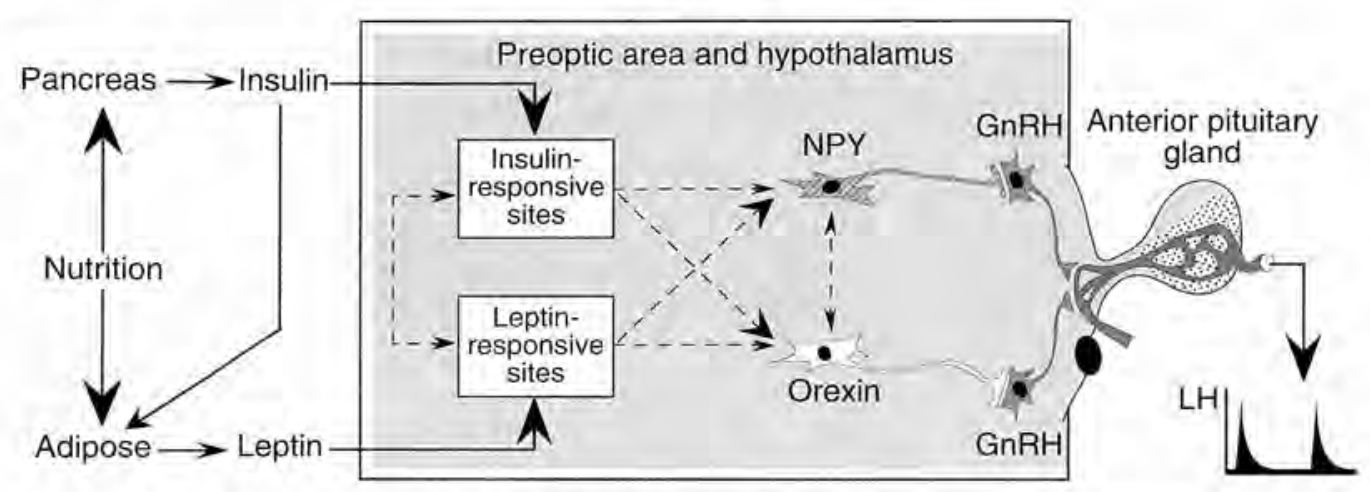

Fig. 3. The basic hypothesis underlying our studies of the pathways via which nutrition influence brain reproductive centres and their output through the 'final common pathway', the GnRH neurones. GnRH neuronal activity is bioassayed by measuring LH pulse frequency. Solid lines indicate pathways for which we have evidence, or which are currently being investigated. Orexin receptors have not yet been located in sheep, but might be found on neuropeptide $Y$ (NPY) and GnRH neurones.

treatments with external manipulation of the $\mathrm{GnRH}$ signals that reach the gonadotrophs, it has shown that the long-term effect of nutrition on testicular mass is partly independent of, and also partly dependent on, hypothalamic GnRH output. The implication is that there are direct actions of metabolic factors on testicular activity and these await study, perhaps after a similar line of investigation, such as the work on responses of the sheep ovary to nutritional stimuli (Muñoz-Gutierrez et al., 2002).

With regard to the pathways involved in short-term effects of nutrition on hypothalamic GnRH output, it appears that signalling from gut to brain involves metabolic hormones, especially leptin and insulin, as well as other gut hormones, such as ghrelin, neuromedin $U$ and amylin (Beck, 2000; Bray, 2000; Rushing et al., 2000; Nakazato et al., 2001). Within the brain, the neuronal pathways through which peripheral nutritional signals modulate the activity of the GnRH cells are still under investigation. The list of neuropeptides that are potential candidates for this role is regularly lengthening, illustrating the complexity and flexibility of the system that regulates GnRH output, the final common pathway from the brain to reproductive axis. As a starting point, we have selected neuropeptides that are involved in pathways that control appetite, especially leptin and insulin, as peripheral signals, and the orexins and neuropeptide $\mathrm{Y}$ (NPY) as neuronal transmitters (Fig. 3). However, a number of other neuropeptides, including cocaine- and amphetamine-regulated transcript (CART), pro-opiomelanocortin (POMC), agouti-related peptide (AgRP), most of which are involved in the control of food intake in rodents (Mercer, 1998; Mercer et al., 2000; Adam and Mercer, 2001), have been localized in the hypothalamus of sheep (Adam et al., 2002). Some of these neuropeptides, in addition to orexins and NPY, might be involved in the processes of signal reception and integration with which the brain appears to 'assess' both food intake and energy balance. For this purpose, we have proposed a neural network that acts as a 'metabolic sensor' receiving inputs from the body in the form of hormonal and neural signals and, through a network of neuropeptides, integrates those signals and then regulates the $\mathrm{GnRH}$ pulse generator (for a review, see Blache et al., 2002).

The nature of these multifactorial, integrative neuronal pathways is covered in detail by Adam et al. (this supplement) so we will broaden the scope of the discussion to cover another level of integration, one that can be illustrated experimentally by the manipulation of a range of environmental and genetic factors. 


\section{Modulators of $\mathrm{GnRH}$ responses to nutrition and interactions between them}

Environmental factors, such as photoperiod, temperature and social milieu, as well as genotype (to the level of breed), all influence the reproductive capacity of rams through the systems that control gamete production and sexual behaviour. Some of these factors modulate the long-, medium- and short-term responses of the reproductive axis to nutrition. Maintaining our focus on the short-term response, namely the increase in GnRH-LH secretion, the effects of three of these modulators: photoperiod, social cues and genotype will be reviewed. The responses to photoperiod and social cues cannot be dissociated from the genetic make-up of the animal, so they will be considered as interactions.

\section{Breed and photoperiod}

In perhaps all breeds of sheep, the timing of reproduction is affected by photoperiod, but some breeds respond much more strongly than others, usually reflecting the geographical latitude of their origin (for a review, see Jewel, 1989). In rams, activation of the photoperiodresponsive pathways connected to the reproductive axis leads to a change in the pulsatile secretion of GnRH which, in turn, affects the secretion of gonadotrophins (Lincoln and Short, 1980). Similarly, the effects of nutrition on the gonads are also at least partly mediated by changes in gonadotrophin secretion (Martin el al., 1994b; Hötzel et al., 1995).

Martin et al. (1994b) used Merino sheep, a breed that has its reproductive season in summer and autumn, to reveal the influence of genotype. The timing of the Merino breeding season is primarily controlled by integration of responses to an endogenous annual rhythm and changes in photoperiod, just as it is in the Suffolk breed, but Merinos are not as strongly affected by photoperiod as the Suffolk breed (Martin et al., 1999, 2002). This effect of genotype on responsiveness to photoperiod also affects responsiveness to nutritional stimuli. In Merino rams, the time of the year has no major influence on the response of the GnRH neurones to stimulation by nutrition (Fig. 4). However, in Suffolk rams, LH pulse frequency increases in response to a lupin supplement during the breeding season, but not during the non-breeding season when the reproductive axis is dominated by the inhibitory effects of photoperiod (Fig. 4). This response is observed in other breeds that respond strongly to photoperiod, such as Scottish Blackface and Finnish Landrace-Dorset cross (Alkass et al., 1982). Thus, photoperiod modulates the effect of nutritional signals on the GnRH pulse generator, but this interaction depends on the genetic make-up of the animal - nutrition can influence the $\mathrm{GnRH}$ pulse generator only when there is no inhibitory effect of photoperiod, either because the photoperiod is stimulatory for photosensitive genotypes, or because it is virtually irrelevant (genotypes that are not very photosensitive).

\section{Socio-sexual cues}

The introduction of rams induces ovulation in anoestrous ewes through a phenomenon known as the 'male effect'. If oestrous ewes accompany the rams, the ovulatory response of the anoestrous ewes is improved, indicating that the oestrous ewes evoke pheromonal and behavioural responses in rams that improve their ability to induce ovulation - a concept termed 'social facilitation' (for a review, see Walkden-Brown et al., 1999). Stimulation of males by females, often called the 'female effect', was first clearly demonstrated in sheep by Sanford et al. (1974) who observed an acute increase in the secretion of LH and testosterone in rams after contact with oestrous ewes. This phenomenon has also been documented for goats, rats, rabbits, cattle and monkeys (Convey et al., 1971; Howland et al., 1985). 

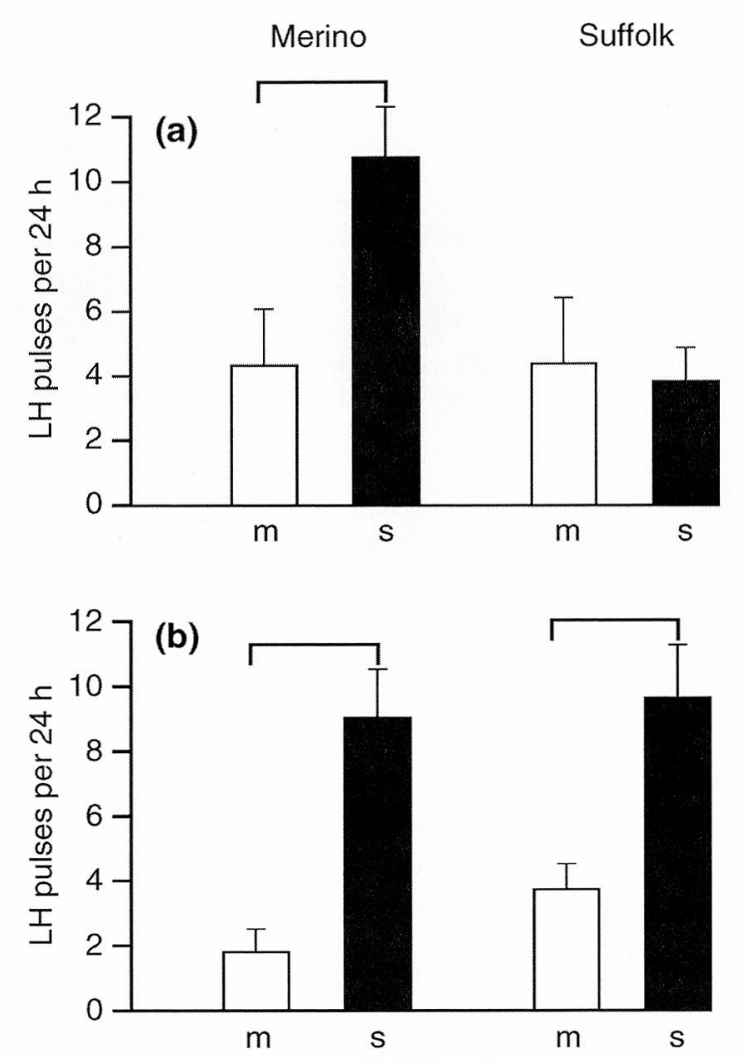

Fig. 4. LH pulse frequency during the (a) nonbreeding and (b) breeding seasons in Suffolk ( $n=$ 5) and Merino rams $(n=6)$ fed a maintenance diet $(\mathrm{m}, \square)$ or the same diet with a supplement of lupin grain $(\mathrm{s}, \mathbf{m})$. On day 12 after the change of diet for the supplemented groups, the lupin treatment had increased LH pulse frequency in both seasons in Merinos $(P<0.003)$, but only during the breeding season $(P<0.003)$ in Suffolks. (Redrawn from Hötzel et al., 2002).

\section{Interactions between socio-sexual cues, photoperiod and genotype}

The size of the response to the female effect is influenced by season (photoperiod), so the percentage of rams responding to oestrous ewes is greater during the non-breeding season than during the breeding season in Finnish Landrace and Ile-de-France rams (Yarney and Sanford, 1983; Gonzalez et al., 1989). This interaction, as well as the effects of genotype and nutrition was investigated by comparing the responses of Merino and Suffolk rams to the introduction of Merino ewes in two seasons. Merino rams responded to the female effect in both the breeding and non-breeding seasons, although the response was smaller in amplitude in the breeding season, whereas Suffolk rams displayed no detectable response in either season (Fig. 5). In both genotypes, an increase in the level of nutrition did not change the response of the GnRH pulse generator to the female effect. Therefore, the nutritional input and social input to the $\mathrm{GnRH}$ pulse generator seem to be independent. However, nutrition seems to have at least a permissive effect because, when rams are well fed, the GnRH system is 
(a)
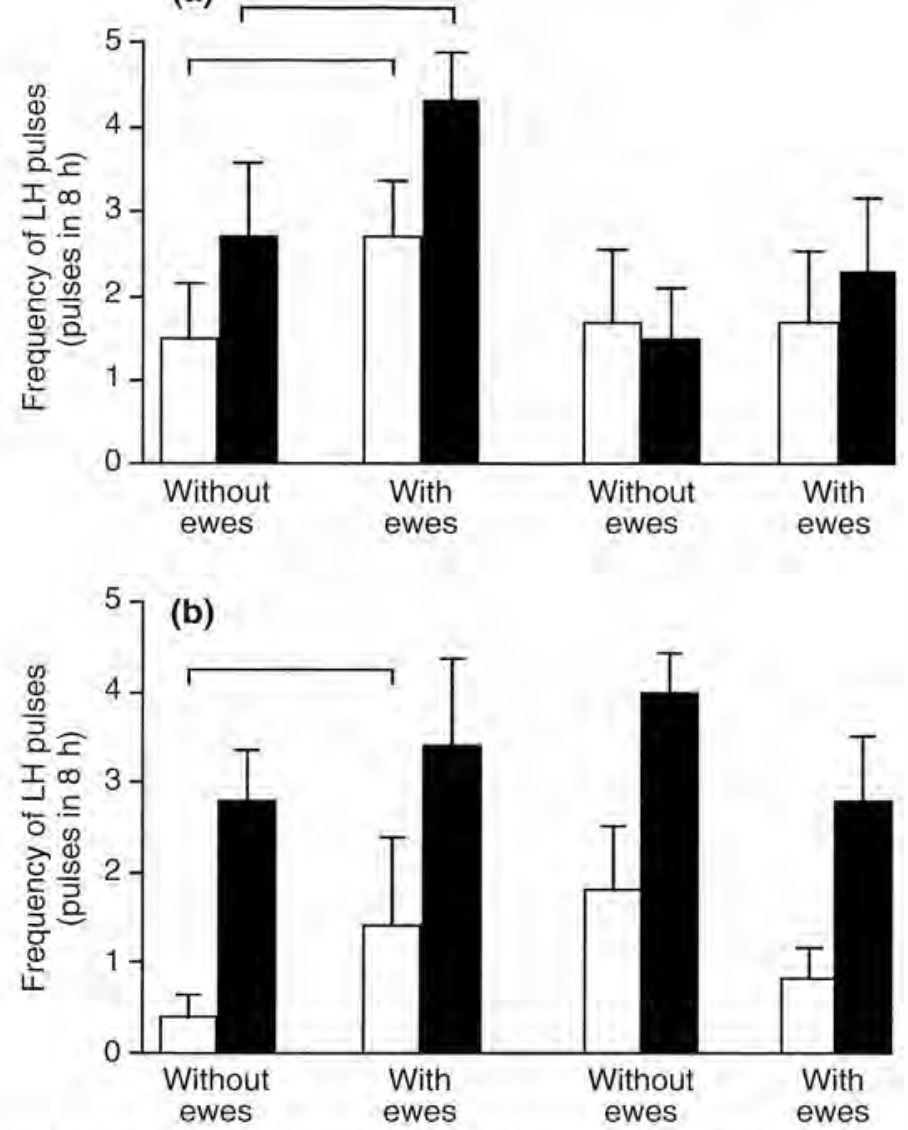

Fig. 5. Frequency of LH pulses in Merino and Suffolk rams fed maintenance $(\square)$ or high energy and protein diet (-) for 13 days during (a) the non-breeding season and (b) the breeding season. The frequencies are measured for $8 \mathrm{~h}(09: 00-17: 00 \mathrm{~h})$ over consecutive days in the absence and presence of oestrous ewes. Differences are indicated at $P<0.05$ (Redrawn from Fisher, 1995).

sensitive to the 'female effect' but when rams are underfed, the GnRH system shuts down and does not respond to socio-sexual cues (Fisher, 1995). Overall, responsiveness to the female effect is largely determined by the genotype of the ram but, in contrast to the situation in goat bucks (Walkden-Brown et al., 1993, 1994), it does not seem to be enhanced by improved nutrition.

\section{Physiological mechanisms involved in modulation of the 'lupin effect'}

In the above description of pathways involved in the 'lupin effect', we made a distinction between signals from the body to the brain and signals within the brain. The same type of distinction needs to be made among the potential pathways involved in the modulatory effects by photoperiod, breed or social cues. In particular, we cannot ignore the profoundly fundamental roles of the gonadal steroids in the control of GnRH secretion. 


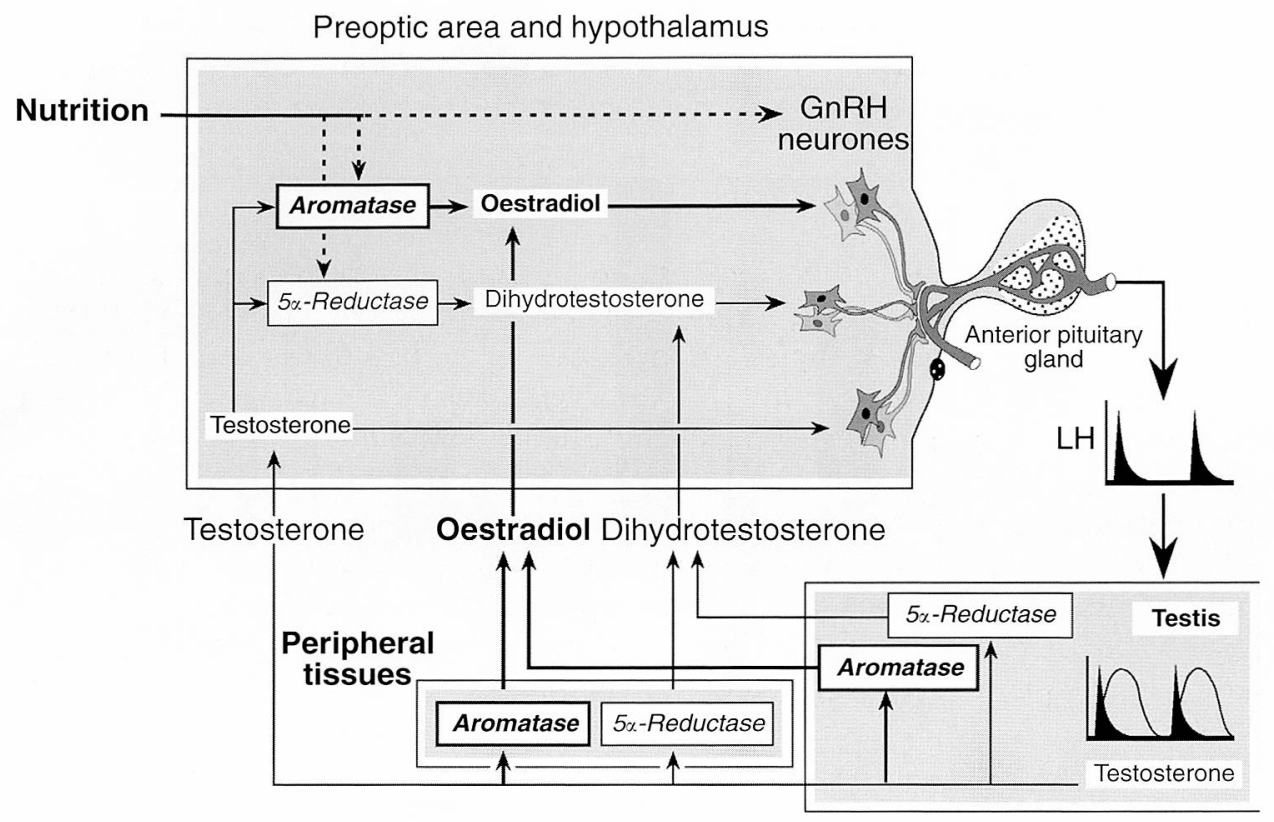

Fig. 6. Schematic summary of the potential involvement of steroid feedback in the effect of nutrition on $\mathrm{GnRH}$ neurones. The gonadotrophins stimulate the production of sex steroids and these feed back to the GnRH neurones, through as yet unknown intermediates, to maintain an equilibrium in the system. The most effective feedback pathways are shown in bold text and thick arrows.

\section{Signals from the testis: steroid feedback}

Responses to castration and steroid replacement completely overshadow the responses to changes in photoperiod, socio-sexual cues or nutrition. Inhibitory feedback by the sex steroids is exerted at sites in the central nervous system that control the frequency of GnRH pulses (Caraty and Locatelli, 1988; Tilbrook et al., 1991), the final common pathway to reproductive axis, and they amplify the responses to socio-sexual signals and changes in nutrition and photoperiod. They also interact with centres that control appetite and, as with the reproductive axis, they amplify the effects of photoperiod thus re-enforcing the link between these two body functions (Godfrey et al., 1996; Walkden-Brown et al., 1997). However, the neuronal pathways linking steroid feedback and nutritional cues have not been studied in detail. This area of research could benefit by using as a blueprint the hypotheses developed to explain seasonal variation in the response of the GnRH system to negative feedback. In rams, the inhibitory effect of testosterone is affected by photoperiod (Lincoln, 1985), nutrition and genotype (Tjondronegoro et al., 1996). Testosterone has been the focus of most of these studies, but the products of its metabolism by $5 \alpha$-reductase (dihydrotestosterone) and aromatase (oestradiol) also inhibit LH secretion in rams (Pelletier, 1974; Schanbacher and Ford, 1977; Blache et al., 1997) (Fig. 6). With respect to oestradiol, we have documented three lines of evidence for the role of central aromatization in control of GnRH output (Sharma, 1999; Sharma et al., 1999). First, i.m. injections of aromatase inhibitor increase the pulsatile secretion of $\mathrm{LH}$ and decrease circulating oestradiol concentrations in testis-intact rams. Second, aromatase inhibitor increases LH pulse frequency and decreases oestradiol concentrations in castrated rams treated with testosterone. Finally, LH pulse frequency increases after infusion of aromatase 
inhibitor into the third ventricle of testis-intact rams. Now that understanding of testicular feedback has gained this extra level of complexity, the interactions between sex steroids and the exteroceptive factors that affect reproduction in males need to be re-addressed.

\section{Signals from metabolism}

The plasma concentrations of metabolites and metabolic hormones depend on metabolic rate, a function of the intake, storage and use of energy. Metabolic rate is affected by photoperiod so, in Soay sheep, for example, it is lower during the breeding season than during the non-breeding season (Argo et al., 1999). This seasonal variation is marked in highly seasonal breeds, such as the Soay, Scottish Blackface and Shetland, and less evident in genotypes that contain 'Mediterranean genes', such as the Dorset Horn (lason et al., 1994). This phenomenon has not been studied in Merinos, but their strong Mediterranean origin leads us to assume that their seasonal variation would be at least as small as that in the Dorset Horn. In addition, seasonal variation in metabolic rate would be expected to be associated with variation in the profiles of metabolites and metabolic hormones, all of which might differ among breeds. This variation could explain the seasonality of the $\mathrm{GnRH}$ response to nutrition in Suffolks (highly seasonal) and the consistent response of Merinos across all seasons. However, the genotype effect seems to be related to the sensitivity to photoperiod, so it might not be possible to dissociate the two factors.

The next question is which signals convey information about these changes in metabolic rate to the brain? A role for metabolic hormonal input to the 'metabolic sensor' is supported by data obtained on the effect of photoperiod on leptin. Plasma concentrations of leptin are lower during the breeding season than the non-breeding season in all seasonal breeders studied to date (Klingenspor et al., 1996; Bocquier et al., 1998; Mann et al., 2000; Marie et al., 2001). In hamsters, low plasma concentrations of leptin result from direct effects of daylength on the systems that control the activity of the adipocytes (Klingenspor et al., 1996). However, in sheep, it is unlikely that genotype influences this because leptin profiles are similar in Merino and Suffolk rams kept under constant nutrition and a Mediterranean-type photoperiod cycle (Fig. 7).

A new development in this area is the recently discovered peptide, ghrelin which is principally produced by the gut. Its production is influenced by acute and chronic changes in nutrition and it appears to be involved in the regulation of energy balance (Horvath et al., 2001). In the raccoon, a hibernator, ghrelin concentrations are influenced by photoperiod and are positively correlated with energy intake (Nieminen et al., 2002). Moreover, melatonin has been found to reduce plasma concentrations of ghrelin in rats (Mustonen et al., 2001), indicating a very direct link with the photoperiod-pineal system that mediates seasonal breeding. Ghrelin is also potentially produced by the hypothalamus (Horvath et al., 2001) so both genotype and photoperiod may modulate the lupin effect on GnRH output. Ghrelin might also be associated with the leptin pathway because, in rats, it antagonizes the action of leptin on food intake (Shintani et al., 2001) and the circulating concentrations of leptin and ghrelin respond inversely to melatonin and photoperiod (Bocquier et al., 1998; Chilliard et al., 1998; Mustonen et al., 2001). The effect of interactions between leptin and ghrelin in the modulation of nutritional responses by photoperiod is a potentially interesting area of research, although it would be only one component of the multiplex peripheral signal that is involved in interactions between nutrition, photoperiod and breed. An obvious addition is the plasma concentrations of insulin, a signal known to be involved in the short-term control of GnRH by nutrition and also affected by photoperiod (Miller et al., 1995; Lincoln and Richardson, 1998). 


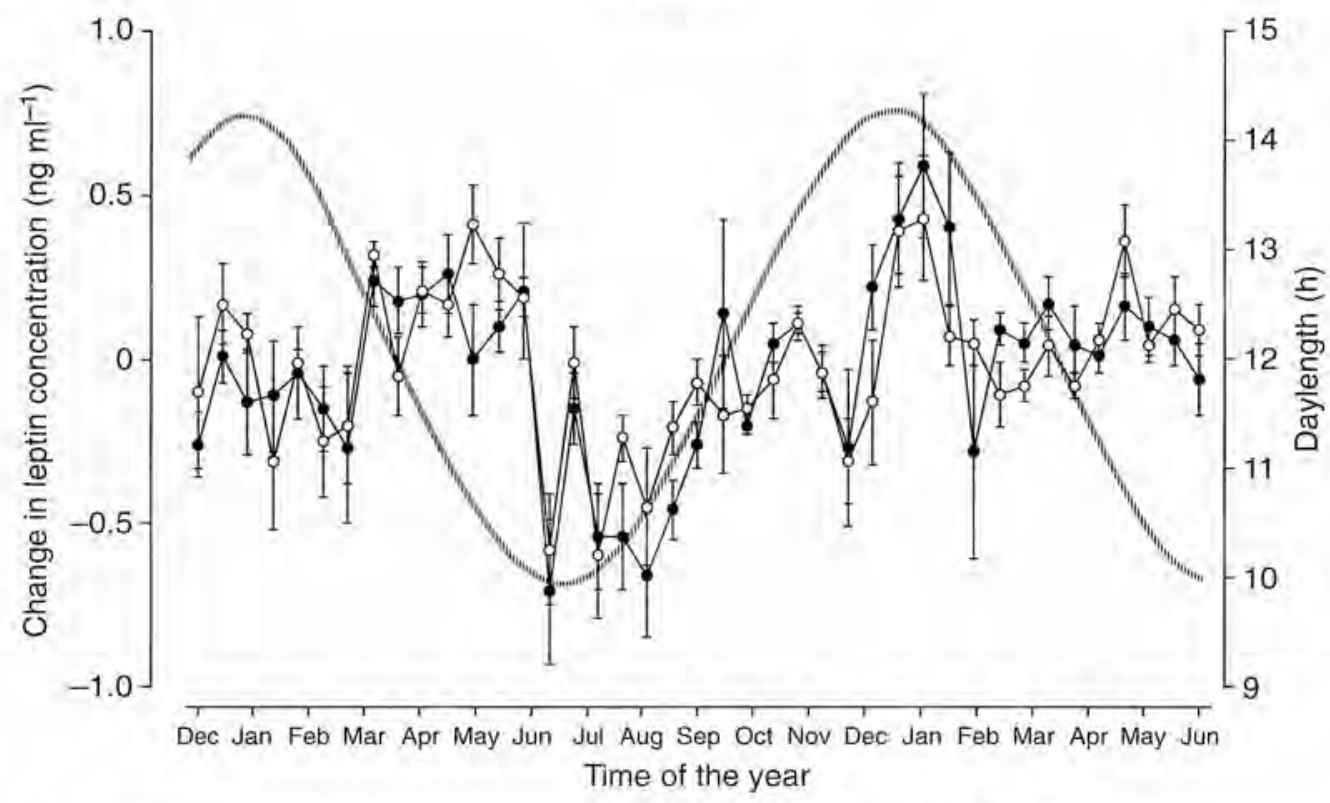

Fig. 7. Change in plasma concentrations of leptin (normalized to the first value measured in Merino $(0)$ and Suffolk $(-)$ rams kept indoors under Mediterranean photoperiod (daylength, hatched line) and fed to maintain constant body weight (for the experimental design, see Martin et al., 1999). Note that the leptin concentrations increase during shortening days but that there is no difference between the two genotypes (D. Blache, unpublished).

\section{Pathways within the brain}

Within the brain, there may be fewer neurohormones that are potential candidates than there are candidates from the body. Among the neuropeptides known to be involved in the control of food intake at the hypothalamus, some are affected by photoperiod and so could mediate the effects of photoperiod on the lupin effect. As will be seen below, and because of the importance of hypothalamic areas in both control of food intake and reproduction, most studies have concentrated on this region of the brain. The control of food intake and its seasonality have been recently and thoroughly reviewed for ruminants (Rhind et al., 2002), so this review will focus only briefly on a few neuropetides that, in our view, are most probably involved in the modulation of the lupin effect.

In sheep, gene expression for NPY is increased by food restriction (Adam et al., 1997; Archer et al., 2000). However, NPY mRNA in the arcuate nucleus is not affected by photoperiod under artificial conditions, but is affected under field conditions (Clarke etal., 2000). This finding indicates that NPY could be involved in a mechanism that integrates photoperiod with parameters of food intake and body condition that are not controlled or measured in the field.

In addition, in sheep, food restriction strongly increases AgRP gene expression but decreases CART gene expression (Archer etal., 1999; Adam, 2000). Expression of both neuropeptides does not appear to be affected by photoperiod, although CART expression is increased by short daylength in Siberian hamsters (Adam et al., 2000; Mercer et al., 2001). As it is likely that AgRP and CART are not sensitive to photoperiod in sheep, these two neuropeptides might only be involved in the modulation of the 'female effect' by undernutrition, although there are no data yet with which to test this hypothesis. 
Results obtained in studies using different genders and steroid replacement protocols have shown that the effect of daylength on POMC gene expression in the hypothalamus of sheep depends on steroid concentrations (Hileman et al., 1996; Archer elal., 1999; Clarke et al., 2000). The sex steroids are necessary for the full effect of photoperiod, nutrition and social cues on GnRH output in rams, so POMC may be involved in responses to any of these factors, although preliminary studies with naloxone indicate that it is not a major component of mechanisms mediating the lupin effect (Martin and Walkden-Brown, 1995).

The expression of mRNA encoding orexins is affected by photoperiod in sheep (Archer et al., 2002). Moreover, the high expression seen during short days is not affected by fasting, indicating that the effect of photoperiod on orexin expression is dominant over the stimulatory effect of fasting on orexins that has been observed in rats (Cai et al., 1999). Therefore, the orexin system might offer an entry point for photoperiod to modulate the effect of nutrition.

We have concentrated on the hypothalamic region, but it is necessary to consider other areas and structures, particularly those from which the primary signals of the modulators are emitted, such as the pineal gland for photoperiod, and the olfactory systems for the sociosexual cues. For example, in rodents, receptors for NPY, orexin and melanin-concentratinghormone receptor have been found in the pineal gland, the hindbrain and the olfactory tract (Mercer et al., 1998; Mikkélsen et al., 1999, 2001; Dal Farra et al., 2000; Saito et al., 2001). Integration can also be achieved at the receptor for both peripheral signals and neuropeptides. Leptin receptor is a good example of this possibility: expression of the gene encoding the active form of the receptor is sensitive to the level of nutrition in female sheep (Dyer et al., 1997).

\section{Integration of the exteroceptive factors}

Clearly, there is a range of candidate signals that could be involved in the interactions between nutrition and other cues that help animals to maximize their chances of successful reproduction. We have seen that some signals, such as leptin, are already part of the conceptual network that we have labelled with the term 'metabolic sensor' (Blache et al., 2000). The same concept of sensor-integrator could be and has been extended to photoperiodic inputs and to socio-sexual inputs because they both involve multiple signalling systems. Superimposed over these, we might expect an even higher level of integration because, as should have become clear from our description of the responses to photoperiodic and socio-sexual cues, the level of nutrition interacts with their effects on the reproductive axis. It is our view that photoperiod exerts a 'filtering' effect on both nutritional and social inputs, and that this filtering effect is determined by genotype (Fig. 8). The mechanisms mediating this filter are not yet understood but we have pointed out some peripheral hormones and neuropeptides that are candidate components of this filter. So far the system that controls the rhythm of pineal melatonin production, a key mediator of the effect of photoperiod has not been mentioned at this stage, we have ruled this out as a filter because first, food supply does not affect the diurnal profile of melatonin in the circulation (Martin et al., 2002) and second, there is little difference between the melatonin patterns in Suffolk and Merino rams despite their very different responses to change in photoperiod (Martin et al., 1999). Other studies have also clearly shown that the pattern of melatonin secretion cannot explain differences in the degree of seasonality among breeds (Kennaway et al., 1982; Ravault and Thimonier, 1988; Schanbacher, 1988). Thus, genotype must be influencing the reproductive axis downstream of the melatonin signal, perhaps at the same site where it influences the way that photoperiod filters the effects of other cues (Fig. 8). 


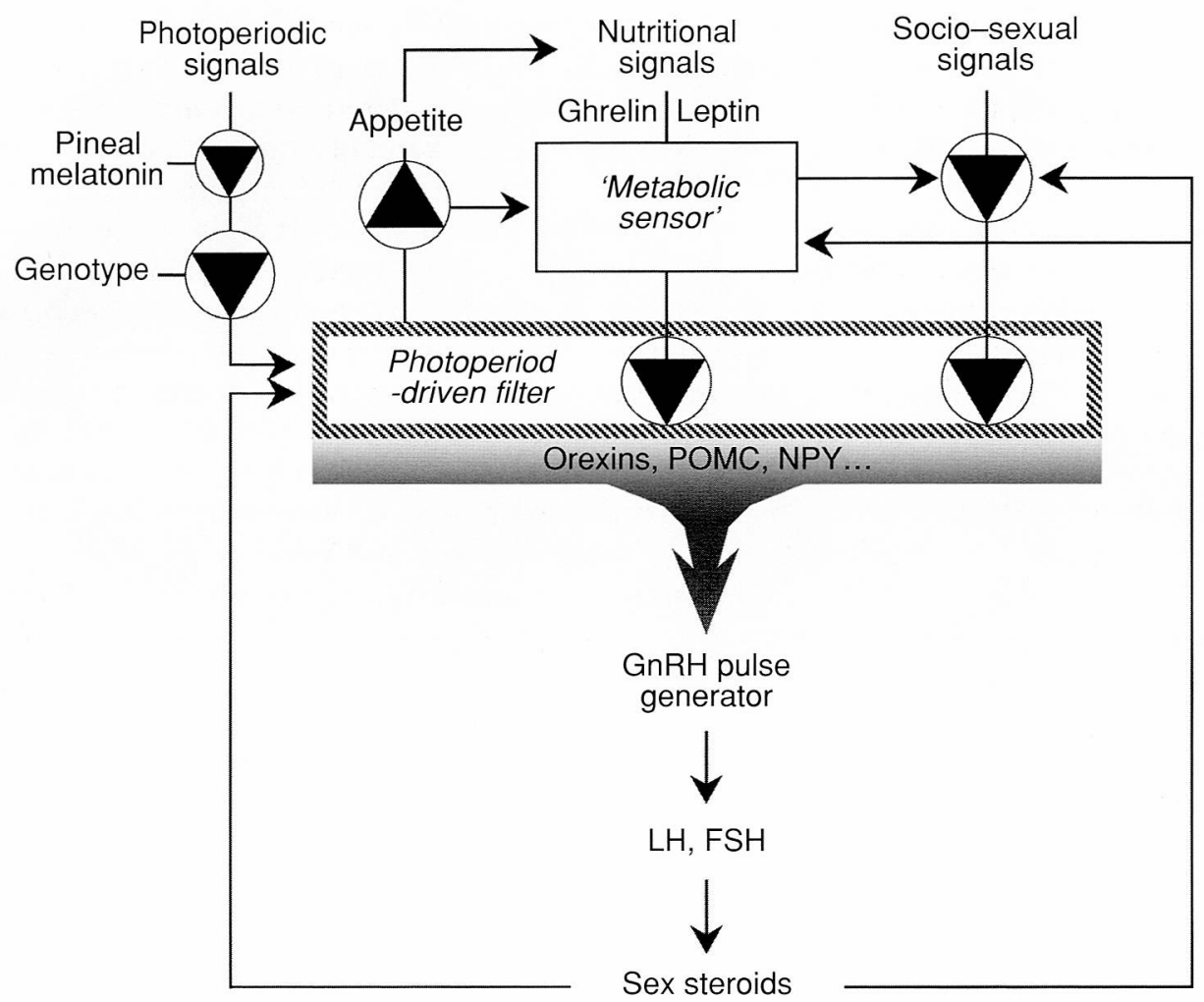

Fig. 8. A schema describing the proposed relationships between photoperiodic, nutritional and social cues and the ways in which they interact with genotype and steroid feedback in the control of hypothalamo-pituitary-testicular axis in male sheep. Some of the hormones and neuropetides that are potentially involved in these interactions are also indicated.

The metabolic sensor can alter the effect of social cues, perhaps even overriding them completely (Fig. 8). Finally, an extra level of complexity is introduced by the brain mechanisms that regulate appetite, particularly in breeds that respond strongly to photoperiod (lason et al., 1994) in which appetite also varies with season. This is a serious issue in studies in which experimental animals are fed ad libitum and, thus, control their own feed consumption, because they will display self-regulated changes in energy metabolism, adiposity and body weight, confounding the responses to treatments. However, this problem can be turned into an investigative advantage because, in photoresponsive breeds, the links between the systems that control appetite and the reproductive axis can be explored to gain an insight into the brain pathways involved.

\section{Conclusion}

With our model based on mature rams acutely fed a supplement of lupin grain, it has been shown that the systems that mediate the effect of nutrition on GnRH output can be modulated by other factors, such as photoperiod, genotype and socio-sexual signals that are known to affect the activity of the reproductive axis. These exteroceptive factors seem to affect the activity of the GnRH pulse generator in a hierarchical manner, with some factors dominating others. 
In addition, the relative importance of photoperiod and nutrition is governed by genotype. The neural and hormonal network(s) involved are a long way from being identified and, in the beginning at least, the resolution of individual pathways will require a primarily reductionist approach to investigation, starting with single gene products and single exteroceptive factors. However, as we have been emphasizing for almost 20 years, 'when measuring any aspect of reproductive function, we must ultimately take into account all of the environmental factors, not only to ensure that our experimental design is not confounded, but also in order to remind ourselves that animals outside the laboratory are rarely confronted with only one stimulus at a time' (Martin, 1984). Therefore, we must always be prepared to expand our view to consider interactions between the various exteroceptive factors and, of course, to accept the roles that are being played by systems controlled by multiple genes.

The authors would like to thank M. Blackberry for her endless help with the hormone assays that make this work possible. S. Zhang is supported by an International Postgraduate Research Scholarship. These studies could not have contemplated without the generous assistance of the students and staff of the Animal Science Group (University of WA), particularly R. Armstrong, J. Catling, J. Fisher, S. Walkden-Brown, M. J. Hötzel and R. Boukhliq. Funding was supplied by the National Health and Medical Research Council, the Australian Research Council, the CSIRO Division of Animal Production, the Australian Wool Corporation, the University of WA, the EHB Lefroy Fellowship and the Brazilian Research Council (CNPq). The authors are also grateful to the National Institute of Diabetes, Digestive and Kidney Disease and A. F. Parlow (Pituitary Hormones and Antisera Center, Harbour-UCLA Medical Center, 1000 Carson Street, Torrance, CA) for the reagents for the gonadotrophin assảys.

\section{References}

Adam CL (2000) Nutritional and photoperiodic regulation of appetite and reproduction in seasonal domestic mammals Reproduction in Dontestic Animals Supplement 6 1-8

Adam CL and Mercer JG (2001) Hypothalamic neuropeptide systems and anticipatory weight change in Siberian hamsters Physiology and Behavior 74 709-715

Adam CL, Findlay PA, Kyle CE, Young P and Mercer JG (1997) Effect of chronic food restriction on pulsatile luteinizing hormone secretion and hypothalamic neuropeptide $Y$ gene expression in the castrate male sheep Journal of Endocrinology 152 329-337

Adam CL, Moar KM, Logie TJ, Ross AW, Barrett P, Morgan PJ and Mercer JG (2000) Photoperiod regulates growth, puberty and hypothalamic neuropeptide and receptor gene expression in female Siberian hamsters Endocrinology 141 4349-4356

Adam CL, Archer ZA, Findlay PA, Thomas L and Marie M (2002) Hypothalamic gene expression in sheep for cocaine-and amphetamine-regulated transcript, proopiomelanocortin, neuropeptide $Y$, agouti-related peptide and leptin receptor and responses to negative energy balance Neuroendocrinology 75 250-256

Alkass JE, Bryant JJ and Walton JS (1982) Some effects of level of feeding and body condition upon sperm production and gonadotropin concentrations in the ram Animal Production 34 265-277

Archer ZA, Rhind SM, Findlay PA, Kyle CE and Adam CL (1999) Effects of food restriction and photoperiod on gonadotrophin secretion and hypothalamic NPY and POMC gene expression in castrate male sheep Journal of Reproduction and Fertility Abstract Series 2357 (Abstract)

Archer ZA, Rhind SM, Findlay PA, Kyle CE and Adam CL (2000) Effects of body condition and increased level of food intake on gonadotrophin $(\mathrm{LH})$ and hypothalamic NPY, AgRP, ObRB and POMC gene expression in castrate male sheep Journal of Reproduction and Fertility Abstract Series 2545 (Abstract)

Archer ZA, Findlay PA, Rhind SM, Mercer IG and Adam CL. (2002) Orexin gene expression and regulation by photoperiod in the sheep hypothalamus Regulatory Peptides 104 41-45

Argo CM, Smith IS and Kay RNB (1999) Seasonal changes of metabolism and appetite in Soay rams Animal Science 69 191-202

Beck B (2000) Neuropeptides and obesity Nutrition 16 916-923

Blache D, Tjondronegoro S, Blackberry MA, Anderson ST, Curlewis JD and Martin GB (1997) Gonadotrophin and prolaction secretion in castrated male sheep following subcutaneous or intracranial treatment with testicular hormones Endocrine 7 235-243

Blache D, Chagas LM, Blackberry MA, Vercoe PE and Martin GB (2000) Metabolic factors affecting the reproductive axis in male sheep Journal of Reproduction and Fertility 120 1-11

Blache D, Adam CL and Martin GB (2002) The mature male sheep: a model to study the effects of nutrition 
on the reproductive axis. In Large Mammals as Neuroendocrine Models pp 219-233. Eds DC Skinner, NP Evans and C Doberska. Society for Reproduction and Fertility, Cambridge

Bocquier F, Bonnet M, Faulconnier Y, Guerre-Millo M, Martin P and Chilliard Y (1998) Effects of photoperiod and feeding level on perirenal adipose tissue metabolic activity and leptin synthesis in the ovariectomized ewe Reproduction, Nutrition and Development 38 489-498

Bray GA (2000) Afferent signals regulating food intake Proceedings of the Nutrition Society 59 373-384

Cai XJ, Widdowson PS, Harrold J, Wilson S, Buckingham RE, Arch JRS, Tadayyon M, Clapham JC, Wilding J and Williams G (1999) Hypothalamic orexin expression - modulation by blood glucose and feeding Diabetes 48 2132-2137

Caraty A and Locatelli A (1988) Effect of time of castration on secretion of LHRH and LH in the ram Journal of Reproduction and Fertility 82 263-269

Chilliard Y, Bocquier F, Delavaud C, Guerre-Millo M, Bonnet $\mathrm{M}$, Martin $\mathrm{P}$, Faulconnier $\mathrm{Y}$ and Ferlay $\mathrm{A}$ (1998) Leptin in ruminants: effect of species, breed, adiposity, photoperiod, beta-agonists and nutritional status Cornell Nutrition Conference for Feed Manufacturers pp 65-74 Cornell University, Ithaca, NY, Rochester NY

Clarke IJ, Scott CJ, Rao A, Pompolo S and Barker-Gibb ML (2000) Seasonal changes in the expression of neuropeptide $Y$ and pro-opiomelanocortin mRNA in the arcuate nucleus of the ovariectomized ewe: relationship to the seasonal appetite and breeding cycles Journal of Neuroendocrinology 12 1105-1111

Convey EM, Bretschneider E, Hafs HD and Oxender WD (1971) Serum levels of LH, prolactin and growth hormone after ejaculation in bulls Biology of Reproduction 91 411-421

Dal Farra C, Zsurger N, Vincent J and Cupo A (2000) Binding of a pure ${ }^{(125)} \mid-m o n o i o d o l e p t i n$ analog to mouse tissues: a developmental study [In Process Citation] Peptides 21 577-587

Dyer CJ, Simmons JM, Matteri RL and Keisler DH (1997) Leptin receptor mRNA is expressed in ewe anterior pituitary and adipose tissues, and is differentially expressed in hypothalamic regions of well-fed and feed-restricted ewes Domestic Animal Endocrinology 14 119-128

Fisher JA (1995) Nutritional and Social Interactions Affecting Reproduction in Seasonally Anoestrous Merino Ewes PhD Thesis, University of Western Australia p 184

Godfrey SI, Walkden-Brown SW, Martin GB and Speijers EJ (1996) Immunisation of goat bucks against GnRH to prevent seasonal reproductive and agonistic behaviour Animal Reproduction Science $\mathbf{4 4}$ 41-54

Gonzalez R, Orgeur P, Poindron P and Signoret J-P (1989) Seasonal variation in LH and testosterone re- sponse of rams following the introduction of oestrous ewes Animal Reproduction Science 21 249-259

Hileman SM, Lubbers LS, Petersen SL, KuehI DE, Scott CJ and Jackson GL (1996) Influence of testosterone on LHRH release, LHRH mRNA and proopiomelanocortin mRNA in male sheep Journal of Neuroendocrinology 8 113-121

Horvath TL, Diano S, Sotonyi P, Heiman M and Tschop $\mathbf{M}$ (2001) Minireview: Ghrelin and the regulation of energy balance: a hypothalamic perspective Endocrinology 142 4163-4169

Hötzel MJ, Walkden-Brown SW, Blackberry MA and Martin GB (1995) The effect of nutrition on testicular growth in mature Merino rams involves mechanisms that are independent of changes in $\mathrm{GnRH}$ pulse frequency Journal of Endocrinology 147 75-85

Hötzel MJ, Walkden-Brown SW, Fisher JS and Martin GB (2002) Determinants of the annual pattern of reproduction in mature male Merino and Suffolk sheep: responses to a nutritional stimulus in the breeding and non-breeding seasons Reproduction, Fertility and Development (in press)

Howland BE, Sanford LM and Palmer WM (1985) Changes in the serum levels of $\mathrm{LH}, \mathrm{FSH}$, prolactin, testosterone and cortisol associated with season and mating in male pygmy goats Journal of Andrology 6 89-96

Iason GR, Sim DA, Foreman E, Fenn P and Elston DA (1994) Seasonal variation of voluntary food intake and metabolic rate in 3 contrasting breeds of sheep Animal Production 58 381-387

Jewel PA (1989) Factors that affect fertility in a feral population of sheep Zoological Journal of the Linnean Society 95 163-174

Kennaway DJ, Gilmore TA and Seamark RF (1982) Effect of melatonin feeding on serum prolactin and gonadotrophin levels and the onset of seasonal oestrous cyclicity in sheep Endocrinology 110 1766-1772

Klingenspor M, Dickopp A, Heldmaier $G$ and Klaus $S$ (1996) Short photoperiod reduces leptin gene expression in white and brown adipose tissue of djungarian hamsters FEBS Letters 399 290-294

Lincoln GA (1979) Differential control of luteinizing hormone and follicle-stimulating hormone by luteinizing hormone releasing hormone in the ram Journal of Endocrinology 80 133-140

Lincoln GA (1985) Central effects of photoperiod on reproduction in the ram revealed by the use of testosterone clamp Journal of Endocrinology 103 233-241

Lincoln GA and Richardson M (1998) Photoneuroendocrine control of seasonal cycles in body weight, pelage growth and reproduction: lessons from the HPD sheep model Comparative Biochemistry and Physiology. Part C. Pharmacology, Toxicology, Endocrinology 119 283-294

Lincoln GA and Short RV (1980) Seasonal breeding: nature's contraceptive Recent Progress in Hormone Research 36 1-52 
Mann DR, Akinbami MA, Gould KG and Castracane VD (2000) A longitudinal study of leptin during development in the male rhesus monkey: the effect of body composition and season on circulating leptin levels Biology of Reproduction 62 285-291

Marie M, Findlay PA, Thomas L and Adam CL (2001) Daily patterns of plasma leptin in sheep: effects of photoperiod and food intake lournal of Endocrinology $170277-286$

Martin GB (1984) Factors effecting the secretion of luteinizing hormone in the ewe Biological Reviews $591-87$

Martin GB and Walkden-Brown SW (1995) Nutritional influences on reproduction in mature male sheep and goats Journal of Reproduction and Fertility Supplement $49437-449$

Martin GB, Walkden-Brown SW, Boukhliq R, Tjondronegoro S, Miller DW, Fisher JS, Hötzel MJ, Restall BJ and Adams NR (1994a) Nonphotoperiodic inputs into seasonal breeding in male ruminants. In Perspectives in Comparative Endocrinology pp 574-585. Eds KG Davey, RE Peter and SS Tobe. National Research Council of Canada, Ottawa

Martin GB, Tjondronegoro $\mathrm{S}$ and Blackberry MA (1994b) Effects of nutrition on testicular size and the concentrations of gonadotrophins, lestosterone and inhibin in plasma of mature male sheep Journal of Reproduction and Fertility 101 121-128

Martin GB, Tjondronegoro S, Boukhliq R, Blackberry MA, Briegel JR, Blache D, Fisher JA and Adams NR (I999) Determinants of the annual pattern of reproduction in mature male Merino and Suffolk sheep: modification of endogenous rhythms by photoperiod Reproduction, Fertility and Development 11 355366

Martin GB, Hötzel MJ, Blache D, Walkden-Brown SW, Blackberry MA, Boukliq R, Fisher JA and Miller DW (2002) Determinants of the annual pattern of reproduction in mature male Merino and Suffolk sheep: modification of response to photoperiod by annual cycle of food supply Reproduction. Fertility and Development 14 165-175

Mercer JG (1998) Regulation of appetite and body weight in seasonal mammals Comparative Biochemistry and Physiology-C Comparative Pharmacology and Toxicology 119 295-303

Mercer JG, Moar KM and Hoggard N (1998) Localization of leptin receptor (Ob-R) mRNA in the rodent hindbrain Endocrinology 139 29-34

Mercer IG, Moar KM, Ross AW and Morgan PJ (2000) Regulation of leptin receptor, POMC and AGRP gene expression by photoperiod and food deprivation in the hypothalamic arcuate nucleus of the male Siberian hamster (Phodopus sungorus) Appetile 34 109-111

Mercer JG, Moar KM, Logie TJ, Findlay PA, Adam CL and Morgan PJ (2001) Seasonally inappropriate bódy weight induced by food restriction: effect on hypothalamic gene expression in male Siberian hamsters Endocrinology 142 4173-4181

Mikkelsen JD, Hauser F and Olcese J (1999) Neuropeptide Y (NPY) and NPY receptors in the rat pineal gland Advances in Experimental Medicine and Biology $46095-107$

Mikkelsen JD, Hauser F, deLecea L, Sutcliffe JG, Kilduff TS, Calgari C, Pevet $\mathbf{P}$ and Simonneaux V (2001) Hypocretin (orexin) in the rat pineal gland: a central transmitter with effects on noradrenaline-induced release of melatonin European lournal of Neuroscience $14+19-425$

Miller DW, Blache D and Martin GB (1995) The role of intracerebral insulin in the effect of nutrition on gonadotrophin secretion in mature male sheep Journal of Endocrinology $147321-329$

Muñoz-Gutierrez M, Blache D, Martin GB and Scaramuzzi R| (2002) Folliculogenesis and the ovarian expression of mRNA for aromatase in anoestrous sheep following five days of glucose or glucosamine infusion or supplementary lupin feeding Reproduction $124721-731$

Mustonen AM, Nieminen P and Hyvarinen $\mathbf{H}$ (2001) Preliminary evidence that pharmacologic melatonin treatment decreases rat ghrelin levels Endocrine $\mathbf{1 6}$ 43-46

Nakazato M, Murakami N, Date Y, Kojima M, Matsuo H, Kangawa K and Matsukura S (2001) A role for ghrelin in the central regulation of feeding Nature 409 194-198

Nieminen P, Mustonen AM, Asikainen J and Hyvarinen H (2002) Seasonal weight regulation of the raccoon dog (Nyctereutes procyonoides) interactions between melatonin, leptin, ghrelin and growth hormone Journal of Biological Rhythms 17 155-163

Pelletier J (1974) Decrease in the pituitary response to synthetic LH-RF in castrated rams following testosterone propianate treatment Journal of Reproduction and Fertility 41 397-402

Ravault JP and Thimonier J (1988) Melatonin patterns in ewes maintained under skeleton or resonance photoperiodic regimens Reproduction. Nutrition, Development 28 473-486

Rhind SM, Archer ZA and Adam CL (2002) Seasonality of food intake in ruminants: recent developments in understanding Nutrition Research Reviews 15 43-65

Rushing PA, Hagan MM, Seeley RJ, Lutz TA and Woods SC (2000) Amylin: a novel action in the brain to reduce body weight Endocrinology 141 850-853

Saito $Y$, Cheng M, Leslie FM and Civelli $O$ (2007) Expression of the melanin-concentrating hormone $(\mathrm{MCH})$ receptor mRNA in the rat brain Journal of Comparative Neurology $43526-40$

Sanford LM, Palmer WM and Howland BE (1974) Influence of sexual activity on serum $\mathrm{LH}$ and testosterone in the ram Ganadian Journal of Animal Science $\mathbf{5 4}$ $579-585$ 
Schanbacher BD (1988) Responses of market lambs and Suffolk rams to a stimulatory skeleton photoperiod Reproduction, Nutrition, Development 28 431-441

Schanbacher BD and Ford JJ (1977) Gonadotrophin secretion in cryptorchid and castrate rams and acute effects of exogenous steroid treatment Endocrinology 100 387-393

Sharma TP (1999) Aromatase and $5 \alpha$-reductase pathways in the control of gonadotrophin secretion in Merino rams: interactions with nutrition. PhD Thesis, University of Western Australia p 127

Sharma TP, Blache D, Blackberry MA and Martin GB (1999) Role of peripheral and central aromatization in the control of gonadotrophin secretion in sheep Reproduction, Fertility and Development $11293-$ 302

Shintani M, Ogawa Y, Ebihara K et al. (2001) Ghrelin, an endogenous growth hormone secretagogue, is a novel orexigenic peptide that antagonizes leptin action through the activation of hypothalamic neuropeptide $\mathrm{Y} / \mathrm{Y} 1$ receptor pathway Diabetes $\mathbf{5 0}$ 227-232

Tilbrook AJ, DeKretser DM, Cummins JT and Clarke IJ (1991) The negative feedback effects of testicular steroids are predominantly at the hypothalamus in the ram Endocrinology 129 3080-3092

Tjondronegoro S, Martin GB, Sutherland SRD and Boukhliq R (1996) Interactions between nutrition, testosterone and inhibin in the control of gonadotrophin secretion in mature rams Reproduction, Fertility and Development 8 855-862

Walkden-Brown SW, Restall BJ and Henniawati (1993) The male effect in the Australian cashmere goat. 3 Enhancement with buck nutrition and use of oestrous females Animal Reproduction Science 32 69-84

Walkden-Brown SW, Restall BJ, Norton BW and Scaramuzzi RJ (1994) The 'female effect' in Australian cashmere goats. Effect of season and diet quality on the $\mathrm{LH}$ and testosterone response of bucks to oestrous does Journal of Reproduction and Fertility $100521-531$

Walkden-Brown SW, Restall BJ, Scaramuzzi RJ, Martin GB and Blackberry MA (1997) Seasonality in male Australian cashmere goats: long term effects of castration and testosterone or oestradiol treatment on changes in LH, FSH and prolactin concentrations, and body growth Small Ruminant Research 26239 252

Walkden-Brown SW, Martin GB and Restall BJ (1999) Role of male-female interaction in regulating reproduction in sheep and goats Journal of Reproduction and Fertility Supplement 54 243-257

Yarney TA and Sanford LM (1983) The reproductiveendocrine response of adult rams to sexual encounters with estrual ewes is season dependent Hormones and Behavior 17 169-182 